\title{
SISTEM PAKAR PROGERIA DI INDONESIA DENGAN MENGGUNAKAN METODA CERTAINTY FACTOR
}

\author{
Yogi Wiyandra 1), Firna Yenila 2), Hari Marfalino ${ }^{3)}$ \\ Universitas Putra Indonesia YPTK Padang1) \\ yogiwiyandra@upiyptk.ac.id, firnayenila@upiyptk.ac.id, harimarfalino@upiyptk.ac.id
}

\begin{abstract}
Abstrak - Penelitian ini bertujuan untuk memberikan informasi kepada masyarakat mengenai progeria. Progeria adalah sejenis penyakit langka yang diderita oleh sebagian orang pada umumnya dan ini merupakan salah satu penyakit penuaan prematur yang bisa dialami semenjak didalam kandungan, bayi atau bahkan remaja. Tidak banyak dari masyarakat yang memahami progeria, keterbatasan pengetahuan itu membuat penyakit ini terkesan terbiarkan hingga tidak ada penanganan sama sekali. Untuk itu dirancang sebuah sistem berbasis pengetahuan dari pakar yang merupakan dokter spesialis anak dan genetik. Kondisi fisik penderita progeria mengalami lompatan usia hingga 8 kali dari orang normal. Penderita Progeria pada umumnya baru disadari ketika melihat kondisi fisik anak tersebut setelah berumur setahun dengan gejala-gejala tertentu. Mengantisipasi hal yang demikian dibuatlah sebuah sistem yang mampu memberikan informasi kepada masyarakat seputar progeria. Sistem yang dibangun adalah sistem pakar dengan menggunakan metoda faktor kepastian (certainty factor). Sistem ini mampu memberikan informasi kepada user mengenai progeria dan bisa memberikan informasi kemungkinan user terkena progeria atau tidak dalam bentuk persentase.
\end{abstract}

\section{Kata kunci: Pirogeria, Sistem Pakar, Certainty Factor, Penyakit Langka}

\section{Latar Belakang}

Progeria merupakan salah satu penyakit langka yang tak jarang di mengerti oleh orang awam. Penyakit ini pernah diteliti oleh Jonatan Huntchinson pada 1886. Namun pada penelitian tersebut belum mendapatkan kesimpulan yang pasti mengenai alasan penuaan yang dialami oleh para pasiennya. Pada 1904, Glifort melanjutkan penelitian tersebut dan memberi nama penyakit tersebut dengan istilah Huntchinson Glifort Progeria Syndrom(HGPS), yang merupakan gabungan dari nama mereka.

Penyakit langka ini pada dasarnya lebih banyak menyerang balita yang diperkirakan berusia enam bulan hingga tiga setengah tahun. Penderita progeria pada saat lahir akan terlihat normal sama seperti anak-anak pada umumnya, perubahannya akan terlihat pada usia diatas enam bulan. Dalam Jurnal yang ditulis oleh Sachin kumar, dkk dijelaskan bahwa ciri-ciri seorang balita terkena penyakit progeria adalah terjadi perubahan pada kulit dan rambut. Perubahan tersebut mulai terlihat pada rentan usia 6-12 bulan. Untuk kulit, terjadinya pengurangan jaringan lemak pada kulit yang akhirnya menyebabkan kulit keriput, serta kerontokan pada rambut secara signifikan. Selain itu juga terjadi perubahan pada wajah. Hidung mulai berbentuk seperti paruh, kening bertambah besar, gigi geliginya terlambat tumbuh dan bahkan ada beberapa kasus yang tak tumbuh. Meskipun begitu, mata dari penderita progeria tidak mengalami perubahan hanya terjadi pembesaran pada kantung mata layaknya orang tua.

Banyak diantara kita yang tidak memahami sindrom tersebut, sehingga menganggap biasa atau malah tidak memperhatikan sama sekali. Untuk itu penulis memberikan rancangan sebuah sistem yang baru berupa aplikasi pemrograman yang berbasis web yang memudahkan user dalam mendapatkan informasi mengenai progeria. Sistem ini merupakan sistem pakar yang mendapatkan informasi dari kesimpulannya berdasarkan ilmu dari pakar kesehatan. Dalam penentuan kesimpulan dari sistem pakar ini menggunakan metoda certainty factor dengan tujuan untuk mengetahui berapa persentase kemungkinan pasien terkena sindrom progedia.

\section{Kajian Pustaka}

Muniah, Y (2012) menyatakan bahwa artificial intelligence yang menggunakan pengetahuan-pengetahuan khusus dan juga spesifik yang dimiliki oleh para ahli atau pakar dalam memecahkan masalah tertentu, dan menurut Yogi Wiyandra dkk (2018) bahwasanya Pengetahuan tentang sistem pakar dibentuk dari kaidah atau pengalaman tentang prilaku elemen dari domain bidang pengetahuan tertentu.Pengetahuan pada sistem pakar diperoleh dari orang yang mempunyai pengetahuan pada suatu bidang (pakar bidangtertentu), buku-buku, jurnal ilmiah, majalah, maupun dokumentasi cetak lainnya. Sumber pengetahuan tersebut bisa dikenal dengan sumber keahlian. 


\subsection{Komponen Sistem Pakar}

Komponen sistem pakar menurut Bambang Yuwono (2015) terdiri atas komponen-komponen yang dijelaskan berikut ini.

\section{a. Antar muka pengguna (user interface)}

Adalah mekanisme yang digunakan oleh pengguna sistem pakar untuk berkomunikasi.

b. Basis pengetahuan (knowledge base)

Basis pengetahuan merupakan kumpulan pengetahuan bidang tertentu pada tingkatan pakar dalam format tertentu. Perkembangan ini disebabkan karena pengetahuan selalu bertambah, terupdate.

Ada dua bentuk pendekatan basis pengetahuan yang sangat umum digunakan:
1. Rule Base Reasoning (Penalaran Berbasis Aturan)
2. Case Based Reasoning (Penalaran Berbasis Kasus)
c. Fasilitas Akuisisi Pengetahuan (Knowledge Acquisition)

Akuisisi pengetahuan adalah proses pengumpulan, perpindahan dan transformasi dari keahlian pemecahan masalah yang berasal dari beberapa sumber pengetahuan kedalam bentuk yang dimengerti oleh komputer.

d. Mesin inferensi (Inference Engine) Mesin inferensi merupakan program komputer yang menyediakan suatu metodologi untuk penalaran tentang informasi dalam basis pengetahuan dan dalam memori kerja untuk merumuskan kesimpulan.

e. Memori Kerja

Memori kerja yang digunakan untuk menyimpan fakta-fakta yang diperoleh saat dilakukan proses konsultasi. Konklusinya bisa berupa hasil diagnosa, tindakan, akibat.

f. Fasilitas Penjelas (Explaining Facility) Salah satu fitur yang harus dimiliki oleh sistem pakar adalah kemampuan untuk menalar. Jika keahlian-keahlian sudah tersimpan sebagai basis pengetahuan dan sudah tersedia program yang mampu mengakses basis data, maka komputer harus dapat diprogram untuk membuat inferensi.

Sistem pakar terbagai atas dua bagian penting diantaranya lingkungan pengembangan (development, environment) dan lingkungan konsultasi (consultation, environment). Konsultasi Lingkungan pengembangan digunakan oleh pembuat sistem pakar untuk membangun komponen-komponennya dan memperkenalkan pengetahuan ke dalam knowledge base (basis pengetahuan). Gambar 2.1 dibawah ini menunjukkan komponen-komponen yang penting dalam sebuah sistem pakar (Sutojo dkk, 2011).

\section{Gambar 2.1 Struktur Sistem Pakar}

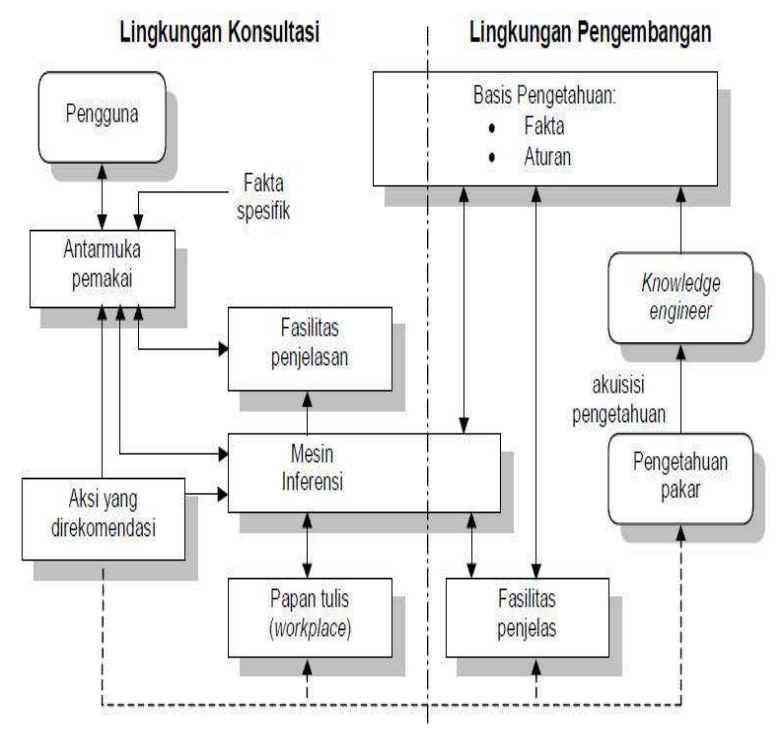

2.3 Motor Inferensi (Inference Engine)

Motor inferensi mengandung mekanisme pola pikir dan penalaran yangdigunakan oleh pakar dalam menyelesaikan suatu masalah dalam Sistem Pakar, yaitu menggunakan metoda Forward Chaining dan Backward Chaining, certainty Factor dll.

Menurut David McAllister, certainty factor adalah suatu metode untuk membuktikan fakta bisa dikakatan pasti atau tidak yang berbentuk metric yang biasanya digunakan dalam sistem pakar. Metode ini sangat cocok untuk sistem pakar yang mendiagnosis sesuatu yang belum pasti. Faktor kepastian (certainty factor) diperkenalkan oleh Shortliffe Buchanan dalam pembuatan MYCIN. Certainty Factor (CF) merupakan nilai parameter klinis yang diberikan MYCIN untuk menunjukkan besarnya kepercayaan. Secara umum rule direpresentasikan dalam bentuk sebagai berikut:

$$
\begin{gathered}
\text { IF E1 [AND / OR] E2 [AND / OR] ... En } \\
\text { THEN H }(\mathrm{CF}=\mathrm{CFi})
\end{gathered}
$$


E1 ... En : fakta - fakta (evidence) yang

ada.

$\mathrm{H}$ : hipotesa atau konklusi yang dihasilkan.

$\mathrm{CF}$ : tingkat keyakinan (Certainty Factor)

terjadinya hipotesa $\mathrm{H}$ akibat adanya fakta

- fakta E1 s/d En.

Menurut David McAllister Certainty Factor adalah suatu metode untuk membuktikan apakah suatu fakta itu pasti ataukah tidak pasti yang berbentuk metric yang biasanya digunakan dalam sistem pakar. Metode ini sangat cocok untuk sistem pakar yang mendiagnosis sesuatu yang belum pasti.

Aturan metode Certainty Factors:

1. McAllister menggambarkan aturan untuk menambahkan dua faktor Certaint positif

2. Aturan untuk menambahkan dua Certaint yang negatif

3. Aturan untuk menambahkan Certainty Factors positif dan Certainty Factors negatif lebih kompleks

4. Aturan ini menyediakan suatu skala interval untuk Certainty Factors. Contoh untuk fakta yang positif: Strong suggestive (CFa): 0.8 Suggestive (CFb) : 0.6 CFcombine $(\mathrm{CFa} \mathrm{CFb})=0.8+0.6$ $(1-0.8)=0.92$

Contoh untuk fakta yang negatif: Strong suggestive (CFc): -0.8 Suggestive (CFd) : -0.6 CFcombine (CFc CFd) $=-0.8+-$ $0.6+-0.8$ * $-0.6=-0.92$ Contoh untuk fakta yang positif dan negatif: Certainty factor adalah 0.88 (CFe)

Certainty factor against adalah 0.90 (CFf)

Metode certainty factors ini hanya bisa mengolah dua bobot dalam sekali perhitungan. Untuk bobot yang lebih dari 2 banyaknya, untuk melakukan perhitungan tidak terjadi masalah apabila bobot yang dihitung teracak, artinya tidak ada aturan untuk mengkombinasikan bobotnya, karena untuk kombinasi seperti apapun hasilnya akan tetap sama. Untuk mengetahui apakah seorang pasien tersebut menderita penyakit jantung atau tidak, itu dilihat dari hasil perhitungan bobot setelah semua keluhankeluhan diinputkan dan semua bobot dihitung dengan menggunakan metode certainty factors. Pasien yang divonis mengidap penyakit jantung adalah pasien yang memiliki bobot mendekati +1 dengan keluhankeluhan yang dimiliki mengarah kepada penyakit jantung. Sedangkan pasien yang mempunyai bobot mendekati -1 adalah pasien yang dianggap tidak mengidap penyakit jantung, serta pasien yang memiliki bobot sama dengan 0 diagnosisnya tidak diketahui atau unknown atau bisa disebut dengan netral.

$$
C F(H, E)=M B(H, E)-M D(H, E)
$$

$\mathrm{CF}(\mathrm{H}, \mathrm{E})$ : certainty factor dari hipotesis $\mathrm{H}$ yang dipengaruhi oleh gejala (evidence) E.Besarnya CF berkisar antara -1 sampai dengan 1. Nilai -1 menunjukkan ketidakpercayaan mutlak sedangkan nilai 1 menunjukkan kerpercayaan mutlak.

$\mathrm{MB}(\mathrm{H}, \mathrm{E})$ : ukuran kenaikan kepercayaan(measure of increased belief) terhadap hipotesis $\mathrm{H}$ yang dipengaruhi oleh gejala $\mathrm{E}$.

$\mathrm{MD}(\mathrm{H}, \mathrm{E})$ : ukuran kenaikan ketidakpercayaan (measure of increased disbelief) terhadap hipotesis $\mathrm{H}$ yang dipengaruhi oleh gejala $E$ Bentuk dasar rumus certainty factor sebuahaturan JIKA E MAKA H adalah seperti ditunjukkan oleh persamaan 2 berikut:

$$
\mathrm{CF}(\mathrm{H}, \mathrm{e})=\mathrm{CF}(\mathrm{E}, \mathrm{e}){ }^{*} \mathrm{CF}(\mathrm{H}, \mathrm{E})
$$

Dimana

$C F(E, e)$ : certainty factor evidence $E$ yang dipengaruhi oleh evidence e

$\mathrm{CF}(\mathrm{H}, \mathrm{E})$ : certainty factor hipotesis dengan asumsi evidence diketahui dengan pasti, yaitu ketika $\mathrm{CF}(\mathrm{E}, \mathrm{e})=1$

$\mathrm{CF}(\mathrm{H}, \mathrm{e})$ : certainty factor hipotesis yang dipengaruhi oleh evidence e Jika semua evidence pada antecedent diketahui dengan pasti maka persamaannya akan menjadi:

$\mathrm{CF}(\mathrm{H}, \mathrm{e})=\mathrm{CF}(\mathrm{H}, \mathrm{E})$

Dalam aplikasinya, $\mathrm{CF}(\mathrm{H}, \mathrm{E})$ merupakan nilai kepastian yang diberikan oleh pakar terhadap suatu aturan, sedangkan $\mathrm{CF}(\mathrm{E}, \mathrm{e})$ merupakan nilai kerpercayaan yang diberikan oleh pengguna terhadap gejala yang dialaminya. Sebagai contoh, berikut ini adalah sebuah aturan dengan CF yang diberikan oleh seorang pakar:

JIKA batuk

DAN demam

DAN sakit kepala

DAN bersin-bersin

MAKA influensa, CF: 0,7

Kelebihan dan Kekurangan Metode

Certainty Factors

\section{Perancangan Sistem}

Pada sistem pakar untuk analisa penentuan dalam melakukan penganalisaan terhadap progeria dimulai dengan pembuatan basis pengetahuan. Pengetahuan yang berasal dari pakar tersebut dipresentasikan ke dalam bentuk-bentuk pengetahuan yang nantinya menghasilkan informasi. 
Proses penalaran dimulai dari sekumpulan data yang menuju pada suatu kesimpulan. Penalaran maju dimulai dengan user menentukan gejala-gejala yang ditemukan. Berdasarkan gejala tersebut user dapat melihat masalah yang ditemukan. Kemudian user dapat menemukan hasil/kesimpulan dari permasalahan yang dihadapi berdasarkan sistem tersebut. Pengumpulan data dilakukan dengan cara wawancara dan konsultasi dengan pakar yang bergerak dibidang spesialis anak. Nantinya diharapkan dapat membantu peneliti dalam pembuatan program sistem pakar yang dapat ditujukan untuk menganalisa program penuaan dini atau progeria yang menghasilkan kesimpulan dan saran. Sistem pakar ini merupakan software yang berusaha menduplikasikan fungsi seorang pakar dalam satu bidang keahliannya, yang bertindak sebagai konsultan yang cerdas atau penasehat yang dapat memberikan suatu hasil/kesimpulan dan saran dalam lingkungan keahlian tertentu namun tidak mengalihkan posisi aslinya para ahli akan tetapi hanya mengaplikasikan pengetahuan para ahli dalam bentuk aplikasi. Dari sistem tersebut dapat dilihat masalah yang ditemukan hingga kesimpulan bisa diberikan sesuai dengan diagnosa awal serta solusi atau saran dari permasalahan yang dihadapi seseorang pada analisa penentuan aktifitas progeria terjawab sesuai keinginan seperti pada Tabel 1.

Tabel 1. Gejala progeria

\begin{tabular}{|c|c|}
\hline Kode & Nama Gejala \\
\hline G1 & $\begin{array}{l}\text { Suaranya nyaring dan bernada } \\
\text { tinggi. }\end{array}$ \\
\hline G2 & $\begin{array}{l}\text { Kulit keriput, muncul bintik-bintik, } \\
\text { dan menipis. }\end{array}$ \\
\hline G3 & $\begin{array}{l}\text { Pertumbuhan gigi menjadi lambat } \\
\text { dan tidak normal. }\end{array}$ \\
\hline G4 & $\begin{array}{l}\text { Rambut rontok, termasuk bulu mata } \\
\text { dan alis. }\end{array}$ \\
\hline G5 & $\begin{array}{l}\text { Pembuluh darah di bawah kulit bisa } \\
\text { terlihat jelas. }\end{array}$ \\
\hline G6 & Daun telinga melebar. \\
\hline G7 & $\begin{array}{l}\text { Bentuk bola mata besar menonjol } \\
\text { keluar, dan kelopak mata tidak bisa } \\
\text { tertutup sempurna. }\end{array}$ \\
\hline G8 & $\begin{array}{l}\text { Suaranya nyaring dan bernada } \\
\text { tinggi. }\end{array}$ \\
\hline G9 & $\begin{array}{l}\text { Kulit keriput, muncul bintik-bintik, } \\
\text { dan menipis. }\end{array}$ \\
\hline G10 & $\begin{array}{l}\text { Pertumbuhan gigi menjadi lambat } \\
\text { dan tidak normal. }\end{array}$ \\
\hline G11 & $\begin{array}{l}\text { Rambut rontok, termasuk bulu mata } \\
\text { dan alis. }\end{array}$ \\
\hline G12 & $\begin{array}{l}\text { Lemak tubuh dan otot perlahan } \\
\text { menghilang. }\end{array}$ \\
\hline G13 & $\begin{array}{l}\text { Ukuran kepala tidak } \begin{array}{l}\text { proporsional, } \\
\text { tampak besar } \\
\text { tubuhnya. }\end{array} \\
\text { dibandingkan }\end{array}$ \\
\hline
\end{tabular}

\begin{tabular}{|l|l|}
\hline G14 & $\begin{array}{l}\text { Ukuran wajah menyempit (mungil) } \\
\text { dan rahang bawah lebih kecil. }\end{array}$ \\
\hline G15 & Pendengaran memburuk. \\
\hline G16 & Tulang rapuh. \\
\hline G17 & Dislokasi panggul. \\
\hline
\end{tabular}

Tabel 2. Data Penyakit

\begin{tabular}{|c|l|}
\hline Kode & \multicolumn{1}{|c|}{ Nama Penyakit } \\
\hline P1 & Progeria Stadium 1 \\
\hline P2 & Progeria Stadium 2 \\
\hline P3 & Progeria Stadium 3 \\
\hline P4 & Progeria Stadium Lanjut \\
\hline
\end{tabular}

Tabel 3. Data Solusi

\begin{tabular}{|c|l|l|l|l|}
\hline Kode & P1 & \multicolumn{1}{|c|}{ P2 } & P3 & P4 \\
\hline G1 & V & & & \\
\hline G2 & & & & \\
\hline G3 & & V & V & V \\
\hline G4 & & & & V \\
\hline G5 & V & V & & \\
\hline G6 & & & V & V \\
\hline G7 & & V & V & V \\
\hline G8 & & & & V \\
\hline G9 & V & V & V & V \\
\hline G10 & & V & & V \\
\hline G11 & & V & V & V \\
\hline G12 & & V & & V \\
\hline G13 & & V & V & V \\
\hline G14 & & & V & V \\
\hline G15 & & & & V \\
\hline G16 & & & V & V \\
\hline G17 & & & & V \\
\hline
\end{tabular}

Dari kondisi diatas untuk mengetahui kemungkinan progeria bisa dilakukan kalkulasi sebagai berikut:

Pengguna konsultasi diberi pilihan jawaban yang masing-masing bobotnya sebagai berikut seperti pada tabel 4 .

Tabel 4. Bobot Certainty Factor

\begin{tabular}{|c|l|c|}
\hline No & \multicolumn{1}{|c|}{ Keterangan } & $\begin{array}{c}\text { Nilai } \\
\text { User }\end{array}$ \\
\hline 1 & Tidak & 0 \\
\hline 2 & Tidak Tahu & 0,2 \\
\hline 3 & Sedikit Yakin & 0,4 \\
\hline 4 & Cukup Yakin & 0,6 \\
\hline 5 & Yakin & 0,8 \\
\hline 6 & Sangat Yakin & 1 \\
\hline
\end{tabular}

Tabel 5. Nilai Certainty Factor untuk masing-masing Premis

\begin{tabular}{|l|l|l|}
\hline Kode & Nama Gejala & $\begin{array}{c}\text { Certainty } \\
\text { Rule }\end{array}$ \\
\hline
\end{tabular}




\begin{tabular}{|c|c|c|}
\hline G1 & $\begin{array}{l}\text { Suaranya nyaring dan } \\
\text { bernada tinggi. }\end{array}$ & 0,2 \\
\hline G2 & $\begin{array}{l}\text { Kulit keriput, muncul bintik- } \\
\text { bintik, dan menipis. }\end{array}$ & 0,8 \\
\hline G3 & $\begin{array}{l}\text { Pertumbuhan gigi menjadi } \\
\text { lambat dan tidak normal. }\end{array}$ & 0,4 \\
\hline G4 & $\begin{array}{l}\text { Rambut rontok, termasuk } \\
\text { bulu mata dan alis. }\end{array}$ & 0,8 \\
\hline G5 & $\begin{array}{l}\text { Pembuluh darah di bawah } \\
\text { kulit bisa terlihat jelas. }\end{array}$ & 0,8 \\
\hline G6 & Daun telinga melebar. & 0 \\
\hline G7 & $\begin{array}{l}\text { Bentuk bola mata besar } \\
\text { menonjol keluar, dan } \\
\text { kelopak mata tidak bisa } \\
\text { tertutup sempurna. }\end{array}$ & 0,2 \\
\hline G8 & $\begin{array}{l}\text { Lemak tubuh dan otot } \\
\text { perlahan menghilang. }\end{array}$ & 0,8 \\
\hline G9 & $\begin{array}{l}\text { Ukuran kepala tidak } \\
\text { proporsional, tampak besar } \\
\text { dibandingkan tubuhnya. }\end{array}$ & 0,8 \\
\hline G10 & $\begin{array}{l}\text { Ukuran wajah menyempit } \\
\text { (mungil) dan rahang bawah } \\
\text { lebih kecil. }\end{array}$ & 0,6 \\
\hline G11 & Pendengaran memburuk. & 0,4 \\
\hline G12 & Tulang rapuh. & 0,6 \\
\hline G13 & Dislokasi panggul. & 0,8 \\
\hline G14 & $\begin{array}{l}\text { Penyakit jantung dan } \\
\text { pembuluh darah yang cukup } \\
\text { parah. }\end{array}$ & 0,8 \\
\hline G15 & Resistensi terhadap insulin. & 0,8 \\
\hline G16 & Persendian kaku. & 0,4 \\
\hline G17 & $\begin{array}{l}\text { Jaringan ikat dan kulit } \\
\text { mengeras dan menebal } \\
\text { menyerupai skleroderma. }\end{array}$ & 0,4 \\
\hline
\end{tabular}

\begin{tabular}{|c|l|c|c|}
\hline G4 & $\begin{array}{l}\text { Rambut } \\
\text { rontok, } \\
\text { termasuk } \\
\text { bulu mata } \\
\text { dan alis. }\end{array}$ & Yakin & 0,8 \\
\hline
\end{tabular}

Rule-rule yang baru tersebut kemudian dihitung nilai Certainty Factor pakar dengan Certainty Factor user menggunakan persamaan

$$
\begin{aligned}
\mathrm{CF}(\mathrm{H}, \mathrm{E}) & =\mathrm{CF}(\mathrm{E})^{*} \mathrm{CF}(\text { rule }) \\
& =\mathrm{CF}(\text { user })^{*} \mathrm{CF}(\text { pakar })
\end{aligned}
$$

Langkah yang terakhir adalah mengkombinasika $\mathrm{n}$ nilai CF dari masing-masing rule Kombinasikan CF 1 sampai CF 4 dengan persamaan

$$
\begin{aligned}
& \mathrm{CF} \text { Combine }\left(\mathrm{CF}_{1}, \mathrm{CF}_{2}\right)=\mathrm{CF}_{1}+\mathrm{CF}_{2}{ }^{*}\left(1-\mathrm{CF}_{1}\right) \\
& \begin{aligned}
\mathrm{CF} \text { Combine }\left(\mathrm{CF}_{1}, \mathrm{CF}_{2}\right)=0,2+0,8 *(1-0,2) \\
=0,2+0,25 \\
=0,84 \mathrm{CF}_{\text {old }}
\end{aligned} \\
& \begin{aligned}
\mathrm{CF}_{\text {combine }}\left(\mathrm{CF}_{\text {old }}, \mathrm{CF}_{3}\right)=0,84+0,4 *(1-0,84) \\
=0,84+0,064 \\
=0,90 \mathrm{CF}_{\text {old }}
\end{aligned}
\end{aligned}
$$

$$
\begin{aligned}
\mathrm{CF}_{\text {COMBINE }}\left(\mathrm{CF}_{\text {old }}, \mathrm{CF}_{4}\right)=0,90 & +0,8 *(1-0,90) \\
& =0,90+0,08 \\
& =0,98 \mathrm{CF}_{\text {old }}
\end{aligned}
$$

Prosentase keyakinan $=$ CFCOMBINE $* 100 \%=>$ $0,98 \times 100 \%=98 \%$

\section{Implementasi Sistem dan Hasil}

Fasilitas penjelas pada sistem pakar dirancang dengan tujuan untuk memberikan penjelasan user bagaimana sistem pakar ini dijalankan. Bentuk penjelasannya Menu Form Form ini berguna untuk melihat kondisi user pada saat menggunakan sistem. Pada sistem awal terdapat beberapa tools seperti sekilas progeria, sistem pakar, konsultasi dan penulis, seperti pada gambar 1 berikut:

\section{Gambar 1. Sekilas Progeria}

Dari sistem tersebut juga digambarkan mengenai sistem pakar, penjelasan singkat tentang sistem pakar hingga aktifitas konsultasi. User diminta untuk menjawab setiap pertanyaan 
yang diajukan oleh sistem sesuai dengan kondisi saat ini, sepeti pada gambar 2 berikut.

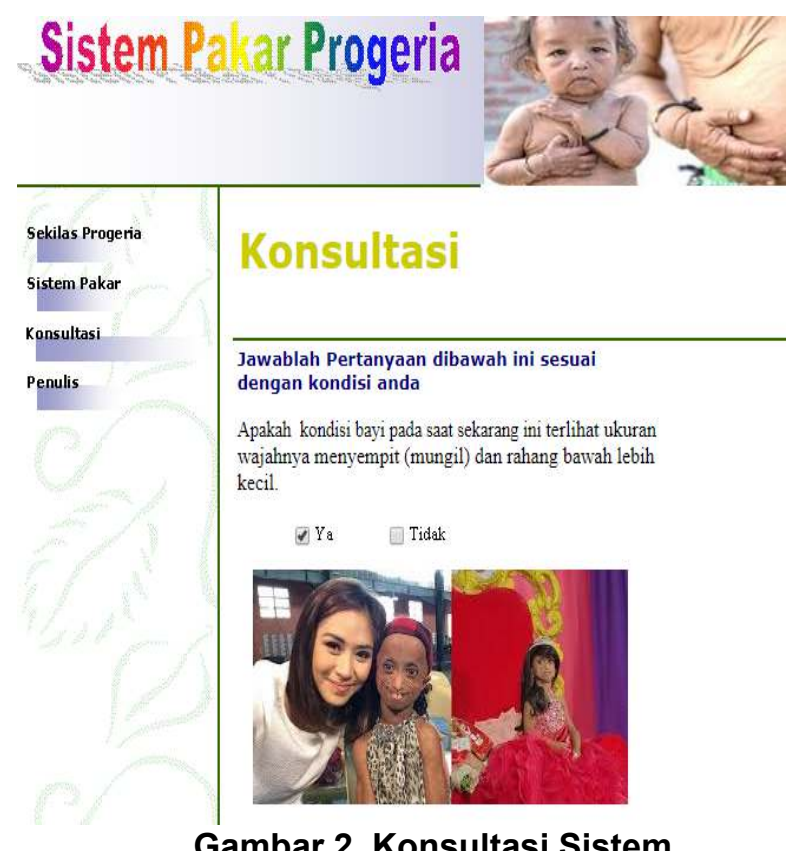

Dari sistem tersebut, dari hasil konsultasi dengan sistem didapatkan kesimpulan dan solusi yang bisa digunakan oleh user berupa hardcopy sebagai berikut:
1. Ada beberapa faktor yang dapat menentukan gejala progeria. Faktor yang mempengaruhi tersebut diperoleh dari beberapa pilihan yang diberikan sistem, sehingga akan dihasilkan perencanaan sistem pakar untuk menentukan pasien mengidap progeria atau tidak

2. Sistem yang dirancang dapat menentukan presentase tingkatan progeria pasien berdasarkan data pilihan user yang dimasukan.

3. Penalaran dilakukan dengan menggunakan metode certainty factor dengan tujuan untuk memberikan persentase kemungkinan progeria-nya pasien.

4. Output dari sistem ini dalam bentuk informasi untuk menghindari progeria atau perawatan bagi penderita progeria dalam tahap awal yang dilihat dengan menggunakan sistem yang berbentuk hard copy.

\section{Pustaka}

Asabere, Yaw, Nana (2012), "Integration Of Expert System In Mobile Learning", ICT Journal, Ghana.

Bambang Yuwono, Simon Pulung Nugroho, Herlyanto, 2015. Pengembangan Model Public Monitoring System menggunakan Raspberry $\mathrm{Pi}$. Jurnal Telematika ISSN 1829-667X Vol. 12 No. 02.

Fitriani, dkk (2012), "Sistem Pakar Pada Bidang Teknologi Informasi Rekomendasi Profesi Pekerjaan - Berdasarkan Kepribadian Mengguanakan Pendekatan Personality Factor", Universitas Brawjaya, Malang.

Gupta, Swati ${ }^{-}$dan $\rightarrow$ singhal, Ritika (2013). \begin{tabular}{l|l}
\hline sekilas Progeria & "Fundamental and Charasteristics Of an \\
& Solusi Expert System". Shobhit University: India.
\end{tabular} sistem Pakar $\quad$ Hartati, Sri dan Iswanti, Sari (2008).

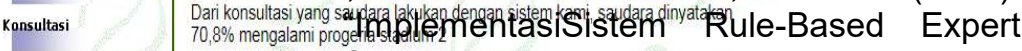

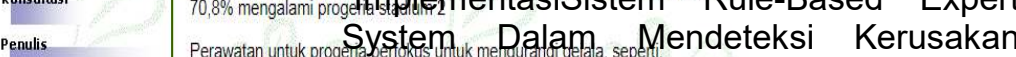
Penulis $\quad$ Perawatan untuk progemalening

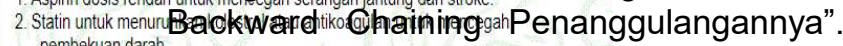

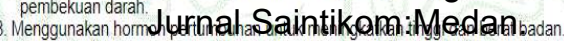

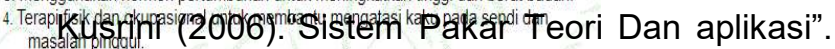

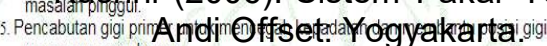

permanenyang buar. dewi, Sri (2003)."Artificial Intelligence Klike disini untuk mencetak (Teknik dan aplikasinya)". Graha IImu: Yogyakarta.
Gambar 3. Solusi

5. Kesimpulan Berdasarkan analisis dan pembahasan yang dilakukan, maka dapat disimpulkan beberapa hal sebagai berikut :
Muniah, Y., Rozlini, M., dan Siti Mariam, Y., 2012, System for Diagnosing Oyster Mushroom Diseases, International Conference on Computer \& Information Science (ICCIS), 12- 14 Juni 2012, 286-289.

Rohman dan Fauziah (2008), "Rancang Bangun Aplikasi Sistem Pakar Untuk Menentukan Jenis Gangguan Perkembangan Pada Design and Rules Development of Expert 
Anak", Universitas Islam Indonesia, Yogyakarta.

Sasmito, dkk (2011). "Aplication Expert System Of Forward Chaining and The Rule Base Reasoning For Simulation Diagnose Pest Disease Red Onion and Chili Plant". ICISBC : Semarang.

Suyanto (2011). "Kecerdasan Buatan". Andi: Yogyakarta.

Wahid, Abdul (2009), "Tuntunan Lengkap Metode Diet Cepsleng”, Garailmu, Yogyakarta.

Wiyandra, Yogi dan Yenila, Firna, 2018, Sistem Pakar Penentuan Kualitas Kendaraan Bekas Pada Basoka motor dengan menggunakan metode forward Chaining, KOMTEKINFO, 26-07-2018 